\title{
Targeted Gene Panel Sequencing for Molecular Diagnosis of Kallmann Syndrome and Normosmic Idiopathic Hypogonadotropic Hypogonadism
}

Authors

Ja Hye Kim¹, Go Hun Seo', Gu-Hwan Kim², Juyoung Huh³ ${ }^{3}$ Il Tae Hwang4, Ja-Hyun Jang ${ }^{5}$, Han-Wook Yoo ${ }^{\text {* }}$, Jin-Ho Choi ${ }^{*}$

\author{
Affiliations \\ 1 Department of Pediatrics, Asan Medical Center Children's \\ Hospital, University of Ulsan College of Medicine, Seoul, \\ Korea \\ 2 Medical Genetics Center, Asan Medical Center, University \\ of Ulsan College of Medicine, Seoul, Korea \\ 3 Asan Institute for Life Sciences, Asan Medical Center, \\ University of Ulsan College of Medicine, Seoul, Korea \\ 4 Department of Pediatrics, Hallym University Kangdong \\ Sacred Heart Hospital, Hallym University College of \\ Medicine, Seoul, Korea \\ 5 Green Cross Genome, Yongin, Korea
}

Key words

anosmia, normosmic idiopathic hypogonadotropic hypogonadism, kallmann syndrome, next-generation sequencing, targeted gene panel

$\begin{array}{ll}\text { received } & 25.05 .2018 \\ \text { revised } & 09.08 .2018 \\ \text { accepted } & 13.08 .2018\end{array}$

Bibliography

DOI https://doi.org/10.1055/a-0681-6608

Published online: 14.9.2018

Exp Clin Endocrinol Diabetes 2019; 127: 538-544

(c) J. A. Barth Verlag in Georg Thieme Verlag KG Stuttgart .

New York

ISSN 0947-7349

\section{Correspondence}

Jin-Ho Choi, MD, PhD

Department of Pediatrics

Asan Medical Center Children's Hospital

University of Ulsan College of Medicine, 88

Olympic-Ro 43-Gil

Songpa-Gu

05505 Seoul

Korea

Tel.: + 82/2/3010 3991, Fax: + 82/2/4733725

jhc@amc.seoul.kr $\circledast$ Figure S1, Table S1, S2, S3, S4 Online content viewable at 10.1055/a-0681-6608

\section{ABSTRACT}

Background Isolated gonadotropin-releasing hormone $(\mathrm{GnRH})$ deficiency (IGD) is classified either as Kallmann syndrome (KS) with anosmia or normosmic idiopathic hypogonadotropic hypogonadism ( $\mathrm{nlHH}$ ) and caused by mutations in more than 30 different genes. Recent advances in next-generation sequencing technologies have revolutionized the identification of causative genes by using massively parallel sequencing of multiple samples. This study was performed to establish the genetic etiology of IGD using a targeted gene panel sequencing of 69 known human IGD genes.

Methods This study included 28 patients with IGD from 27 independent families. Exomes were captured using customized SureSelect kit (Agilent Technologies) and sequenced on the Miseq platform (Illumina, Inc.), which includes a 163,269 bp region spanning 69 genes.

Results Four pathogenic and six likely pathogenic sequence variants were identified in 11 patients from 10 of the 27 families $(37 \%)$ included in the study. We identified two known pathogenic mutations in CHD7 and PROKR2 from two male patients (7.4\%). Novel sequence variants were also identified in 10 probands ( $37 \%$ ) in CHD7, SOX3, ANOS1, FGFR1, and TACR3. Of these, while eight variants $(29.6 \%$ ) were presumed to be pathogenic or likely pathogenic, the remaining two were classified as variants of uncertain significance. Of the two pre-pubertal males with anosmia, one harbored a novel heterozygous splice site variant in FGFR1.

Conclusions The overall diagnostic yield was $37 \%$ of the patients who had undergone targeted gene panel sequencing. This approach enables rapid, cost-effective, and comprehensive genetic screening in patients with $\mathrm{KS}$ and $\mathrm{nlHH}$.

"These two authors contributed equally. 


\section{Introduction}

Isolated gonadotropin-releasing hormone (GnRH) deficiency (IGD) is caused by a defect in $\mathrm{GnRH}$ production, secretion, or action [1]. IGD is classified either as Kallmann syndrome (KS), which is associated with anosmia, or normosmic idiopathic hypogonadotropic hypogonadism $(\mathrm{nlHH})$, wherein patients retain a normal sense of smell [1]. IGD is a genetically heterogeneous disorder that is associated with over 30 causative genes. Over the last 20 years, mutations in several genes and pathways that affect IGD have been identified [2]. In addition, studies have reported that $10-20 \%$ of patients have oligogenic defects in different genes that act synergistically to modify the severity of IGD $[3,4]$.

Certain non-reproductive features (e. g., synkinesia, renal agenesis, dental agenesis, hearing defects, and skeletal abnormalities) are highly linked to specific genetic defects, and these features can prove helpful during prioritization of genes for screening [5]. Traditional Sanger sequencing can provide a genetic diagnosis in cases with distinct phenotypes and the presence of family histories [6]. However, when a proband has no affected family members or associated non-reproductive phenotypic features, serial single-gene or multi-gene panel testing is required for genetic diagnosis [5-7].

Over the last 20 years, significant progress has been made in the understanding of the molecular genetics of IGD. Recent advances in next-generation sequencing (NGS) techniques have enabled massive parallel sequencing of multiple genes. Targeted enrichment techniques have been developed to reduce genome complexity via targeted sequence captures and optimized the coverage of targeted regions for high throughput deep sequencing rather than whole exome sequencing (WES) or whole genome sequencing (WGS) [8]. Therefore, NGS techniques have changed how genetic research assesses genetically heterogeneous diseases. As an example, recent studies that have used NGS technologies have demonstrated numerous candidate genes for IGD, such as OTUD4, FEZF1, STUB1, DMLX2, RNF216, PNPLR6, CCDC14, and SEMA3E11, 9, 10]. Furthermore, targeted NGS of 261 candidate genes in patients with IGD resulted in the identification of 18 new candidate genes and 2 pathogenic mutations in FGFR1[11].

In spite of these studies, NGS techniques are not widely used in clinical practice due to the high cost and complexity of data analysis. We have therefore designed a targeted gene panel for the diagnosis of IGD using 69 known human IGD genes. In sum, this study was performed to apply targeted gene panel testing in clinical practice and to identify the genetic etiology of patients with IGD using targeted gene panel sequencing.

\section{Materials and Methods}

\section{Subjects}

This study involved 28 patients from 27 independent families, including 23 males with IGD (82.1\%), three females with IGD (10.7\%), and two pre-pubertal males with anosmia (7.1\%). A diagnosis of IGD was made according to the following criteria: 1) absent or incomplete pubertal development by the age of 17 years in females and 18 years in males; 2 ) clinical signs or symptoms of hypogonadism; 3) serum testosterone levels of $<1.0 \mathrm{ng} / \mathrm{mL}$ in males or serum estradiol levels of $<20 \mathrm{pg} / \mathrm{mL}$ in females with low or normal levels of gonadotropin; 4) normal thyroid, adrenal, and growth hormone axes; 5) normal magnetic resonance image (MRI) of the hypothalamic and pituitary areas; and 6) the absence of sex chromosome abnormalities [2, 5, 12]. This study was approved by the Institutional Review Board at Asan Medical Center, Seoul, Korea, and informed consent was obtained from all patients or their parents.

\section{Clinical and endocrinological evaluation}

Clinical features were obtained by retrospective review of the patients' medical records, which included data about sense of smell, family history, associated anomalies, history of micropenis, history of cryptorchidism, and laboratory and radiologic findings. Pubertal development was rated according to the guidelines recommended by Marshall and Tanner [13]. Testicular volume was measured with a Prader orchidometer. While olfactory function was evaluated in four patients using the 12 item smell identification test [14], the olfactory function of 24 patients was validated by selfreported history.

\section{Targeted gene panel sequencing and bioinformatics analysis}

Genomic DNA was extracted from peripheral blood leukocytes using the Gentra Puregene Blood Kit (Qiagen, Hilden, Germany). A targeted panel was designed using 69 genes that were known to be involved in hypothalamus/pituitary development [15-23], GnRH neuronal migration [10, 11, 24-34], synthesis and secretion of $\mathrm{GnRH}$ [35-42], IGD associated neurological disorders [43-48], and rare syndromes [26, 30,49-57] associated with hypogonadism (Table 1S, Supporting Information). For comprehensive analysis of the causative genes in IGD, the previously reported IGD-associated genes in human study were selected from the online databases that follows: PubMed (http://www.ncbi.nim.nih.gov/pubmed/), GeneTests (http://www.genetests.org/), and Online Mendelian Inheritance in Man (OMIM, http://www.ncbi.nim.nih.gov/omim/).

We designed oligonucleotide bait tiles against exons and exonintron boundaries within 20 base pairs of 69 genes that spanned an 163,269 bp region. Untranslated regions and promoter regions were not captured. Exomes were captured using a customized Target Enrichment System Kit (Celemics, Seoul, Korea) and then sequenced on the Miseq Platform (Illumina Inc., San Diego, CA, USA). The mean depth of coverage was 163 reads per base. Sequence reads were aligned to the human reference genome (hg19) using the Burrow-Wheeler Alignment program (BWA version 0.7.12). SAMtools 0.1.19 and Genome Analysis Toolkits (GATK version 3.5) were used for single nucleotide polymorphism (SNP) variant calling from aligned sequence reads. GATK version 3.5, FreeBayes 0.9.2.1, and Scalpel-0.5.3 were used for insertion-deletion variant calling. After removing duplicates with PICARD (https://broadinstitute.github.io/picard/), annotation was performed with a Variant Effect Predictor [58].

To reduce the risk of false-positive findings, SNP Phred scores of $\geq 15$ and percent of non-reference calls of $\geq 15$ were analyzed. Variants with minor allele frequencies of $>1 \%$ in the $1000 \mathrm{Genomes}$ Browser (http://browser.1000genomes.org/), NHLBI ESP Exome Variant Server (http://evs.gs.washington.edu/EVS/), and genome Aggregation Database (gnomAD; http://gnomad.broadinstitute.org/) were excluded. Sequence variants were computationally annotated 
using dbSNP (http://www.ncbi.nlm.nih.gov/SNP/)[59] for known polymorphisms, and ClinVar (http://www.ncbi.nlm.nih.gov/clin$\operatorname{var} /$ )[60] and Human Gene Mutation Database (http://www.hgmd. org/)[61] to determine variant pathogenicity. The date of last access for online resources was January 10th, 2018. Rare sequence variants found in targeted gene panel sequencing were confirmed by Sanger sequencing using custom-designed primers. Our sequencing method and algorithm were validated using the NA12878 DNA from the Coriell Cell Repositories of the National Institute of Standards and Technology-led Genome in a Bottle Consortium. Analytic sensitivity, specificity, and reproducibility were $100 \%$, respectively [62].

In silico prediction of the likely effects of novel sequence variants was performed using the following web-based programs: PolyPhen-2 (http://genetics.bwh.harvard.edu/pph2/), Sorting Intolerant From Tolerant(SIFT; http://sift.jcvi.org/), MutationTaster (http://www.mutationtaster.org/), Mutation Assessor (http://www.mutationassessor.org/v1/), and Protein Variation Effect Analyzer (PROVEAN; http:// provean.jcvi.org/) for missense variants, and EX-SKIP (http://ex-skip. img.cas.cz/), Human Splicing Finder (http://www.umd.be/HSF3/), MaxEntScan (http://genes.mit.edu/burgelab/maxent/Xmaxentscan_scoreseq.html), NNSPICE (http://www.fruitfly.org/seq_tools/ splice.html), and SpliceSiteFinder-like (http://www.umd.be/searchsplicesite.html) for splice site variants. Novel sequence variants were classified as being pathogenic, likely pathogenic, a variant of uncertain significance (VUS), likely benign, or benign, in accordance with the guidelines of the American College of Medical Genetics Laboratory Practice Committee Working Group [63].

\section{Results}

\section{Clinical and endocrinological characteristics}

The patients' characteristics are summarized in Table 2S. Among the 26 patients with IGD, 12 (46.2\%) were diagnosed with KS, and $14(53.8 \%)$ were categorized with $\mathrm{nlHH}$. The mean age at presentation in IGD patients was $16.5 \pm 3.1$ years (range, $9-21$ years). A clinical diagnosis of IGD was made after follow up to the age of 17 years in females and 18 years in males; the mean patient age at the time of the study was $22.8 \pm 4.3$ years (range, $18-32$ years). Most patients were sporadic, and all but two male siblings (Subjects 8 and 9), who had been diagnosed with nIHH, had no family history of delayed puberty of IGD. All parents of the patients with IGD had normal fertility.

Micropenis was present in 15 male patients ( 9 with $\mathrm{KS}$ and 6 with $\mathrm{nlHH}$ ), and cryptorchidism was present in 3 males ( 2 with KS and 1 with $\mathrm{nlHH}$ ). Hearing defects were apparent in five patients (four with $\mathrm{KS}$ and one with $\mathrm{nlHH}$ ). Congenital heart disease was noted in three patients with KS (pulmonary atresia and ventricular septal defect). Among 25 IGD patients who underwent brain MRIs, aplasia or hypoplasia of the olfactory bulbs/sulci was detected in 6 of the 12 patients with $\mathrm{KS}$ (50\%). The GnRH stimulation test was performed in 24 IGD patients, wherein peak luteinizing hormone (LH) and follicle-stimulating hormone (FSH) levels were $4.1 \pm 3.4 \mathrm{mIU} / \mathrm{mL}$ and $3.5 \pm 1.7 \mathrm{mIU} /$ $\mathrm{mL}$ in the KS patients, and $5.6 \pm 6.3 \mathrm{mIU} / \mathrm{mL}$ and $5 \pm 4.3 \mathrm{mlU} / \mathrm{mL}$ in the $\mathrm{nIHH}$ patients, respectively (reference range at the onset of puberty: peak LH and FSH levels after $\mathrm{GnRH}$ injection, 12.8 \pm 7.7 and $5.1 \pm 2.8 \mathrm{mlU} / \mathrm{mL}$ in males; $4.9 \pm 2.8$ and $8.1 \pm 2.6$ in females) [64].
Two pre-pubertal males (Subjects 13 and 28) presented with anosmia at 8.1 and 5.8 years, respectively, and aplasia of the olfactory bulbs was seen in both patients. Micropenis and cryptorchidism was observed in Subject 13. While both patients underwent ANOS1 analyses prior to this study, no mutations were detected.

\section{Molecular features of patients with pathogenic or likely pathogenic sequence variants}

Four pathogenic and six likely pathogenic sequence variants were identified in 11 patients from 10 of the 27 families (37\%) included in the study ( $\triangleright$ Table 1, Fig. 1S). Among the patients with pathogenic mutations, Subject 1 was heterozygous for c.5405-7 G > A in CHD7[65], and Subject 3 was heterozygous for a novel nonsense variant of p.Q40 * in CHD7 ( Table 1). These patients were classified as KS with hearing defects. Subject 2 with KS and a history of cryptorchidism was heterozygous for PROKR2 p.W178S, which is known to be pathogenic [66]; brain MRI showed hypoplastic olfactory sulci and bulbs. Two male siblings (Subjects 8 and 9) with homozygous frameshift mutations (p.M176Tfs * 14) in TACR3 exhibited delayed puberty without anosmia at the age of 16 and 20 years of age, respectively.

Likely pathogenic variants were identified in six patients ( $\triangleright$ Table 1 ). Subject 4, with heterozygous p.Y339H mutation in FGFR1, presented with primary amenorrhea without skeletal and olfactory abnormalities. Subject 5, carrying p.N185Kfs * 16 in FGFR1, showed KS with small olfactory bulbs on brain MRI. A novel hemizygous frameshift variant, p.Q421 Kfs * 61 in ANOS1, was identified in Subject 6. Hemizygous in-frame deletion of the polyalanine tract in SOX3 (p.A234_240del) was detected in Subject 7 with nlHH, who presented with delayed puberty, without other anomalies, at 18 years of age. Subject 10, who presented with nIHH and finger syndactyly, harbored a heterozygous variant of c.1855-1 G > A in FGFR1, which was predicted to be damaging by prediction programs (Table 3S). Subject 11 with a history of micropenis and cryptorchidism at birth presented with anosmia at the age of 8 years and was heterozygous for c. $1663+2 \mathrm{~T}>\mathrm{G}$ in FGFR1. This variant was predicted to be deleterious by in silico programs (Table 35 ).

\section{Clinical and molecular findings in patients with variants of uncertain significance}

VUS were identified in two patients with IGD (one with KS and one with nlHH) ( $\triangleright$ Table 2, Fig. 1S). Subject 12 harbored a novel heterozygous VUS of c.3201+4A>G in CHD7. He presented with KS and aplastic olfactory bulbs, as seen on brain MRI. Subject 13 carried a novel heterozygous missense variant of p.S681I in FGFR1, which was not found in normative population databases and was predicted to be deleterious by in silico programs (Table 4S).

\section{Discussion}

This study demonstrated the clinical efficacy of targeted gene panel sequencing in patients with IGD of unknown genetic etiology. Targeted gene panel sequencing achieved genetic diagnosis in $37 \%$ of the patients. Genetic diagnosis using Sanger sequencing is challenging due to clinical and genetic heterogeneity, as well as complex genetic architecture such as oligogenicity. Therefore, target- 
- Table 1 Molecular genetic findings in patients harboring pathogenic or likely pathogenic variants.

\begin{tabular}{|c|c|c|c|c|c|c|c|}
\hline \multirow[t]{2}{*}{ Subject } & \multirow[t]{2}{*}{ Sex } & \multirow{2}{*}{$\begin{array}{l}\text { Age at presenta- } \\
\text { tion (years) }\end{array}$} & \multirow[t]{2}{*}{ Phenotype } & \multicolumn{3}{|c|}{ Sequence variants } & \multirow[t]{2}{*}{ Interpretation } \\
\hline & & & & Gene & Nucleotide change & Amino acid change & \\
\hline 1 & M & 14 & $\begin{array}{l}\text { Kallmann syndrome, } \\
\text { hearing defect }\end{array}$ & CHD7 & c.5405-7 G>A & Splice site & Pathogenic \\
\hline 2 & $\mathrm{M}$ & 21 & Kallmann syndrome & PROKR2 & c. $533 G>C$ & p.W178S & Pathogenic \\
\hline 3 & M & 16 & $\begin{array}{l}\text { Kallmann syndrome, } \\
\text { hearing defect }\end{array}$ & CHD7 & c. $118 C>\mathrm{T}$ & p.Q40* & Pathogenic \\
\hline 4 & $\mathrm{~F}$ & 19 & $\begin{array}{l}\text { nlHH, primary } \\
\text { amenorrhea }\end{array}$ & FGFR1 & c. $1015 \mathrm{~T}>\mathrm{C}$ & p.Y339H & Likely pathogenic \\
\hline 5 & $\mathrm{M}$ & 20 & Kallmann syndrome & FGFR1 & c.551dup & p.N185Kfs*16 & Likely pathogenic \\
\hline 6 & $\mathrm{M}$ & 16 & $\mathrm{nIHH}$ & ANOS1 & c. 1260 del & p.Q421Kfs*61 & Likely pathogenic \\
\hline 7 & $\mathrm{M}$ & 18 & $\mathrm{nlHH}$ & SOX3 & c.699_719del & p.A234_A240del & Likely pathogenic \\
\hline 8 & M & 20 & $\mathrm{nIHH}$ & \multirow[t]{2}{*}{ TACR3 } & \multirow[t]{2}{*}{ c.527_533del/ c.527_533del } & \multirow{2}{*}{$\begin{array}{l}\text { p.M176Tfs * 14/ p. } \\
\text { M176Tfs * } 14\end{array}$} & \multirow[t]{2}{*}{ Pathogenic } \\
\hline 9 & $\mathrm{M}$ & 16 & $\mathrm{nIHH}$ & & & & \\
\hline 10 & $\mathrm{M}$ & 18 & $\mathrm{nIHH}$, finger syndactyly & FGFR1 & c. $1855-1 G>A$ & Splice site & Likely pathogenic \\
\hline 11 & M & 7 & $\begin{array}{l}\text { Anosmia, micropenis, } \\
\text { cryptorchidism }\end{array}$ & FGFR1 & c. $1663+2 T>G$ & Splice site & Likely pathogenic \\
\hline
\end{tabular}

> Table 2 Molecular genetic findings in patients with variants of uncertain significance.

\begin{tabular}{|c|c|c|c|c|c|c|}
\hline \multirow[t]{2}{*}{ Subject } & \multirow[t]{2}{*}{ Sex } & \multirow[t]{2}{*}{ Age at presentation (years) } & \multirow[t]{2}{*}{ Phenotype } & \multicolumn{3}{|c|}{ Sequence variants } \\
\hline & & & & Gene & Nucleotide change & Amino acid change \\
\hline 12 & $\mathrm{M}$ & 19 & KS & CHD7 & c. $3201+4 A>G$ & Splice site \\
\hline 13 & $\mathrm{M}$ & 14 & $\mathrm{nlHH}$ & FGFR1 & c. $2042 \mathrm{G}>\mathrm{T}$ & p.S681I \\
\hline
\end{tabular}

KS, Kallmann syndrome; M, male; nIHH, normosmic idiopathic hypogonadotropic hypogonadism

ed NGS can support the genetic diagnosis of IGD with genetic heterogeneity and oligogenic inheritance.

This study identified an in-frame deletion in the first polyalanine tract of SOX3 in Subject 7, who had been diagnosed with $\mathrm{nlHH}$. The SOX3 gene has a single exon on chromosome Xq26-27 and encodes a transcription factor that is involved in pituitary morphogenesis [67]. The dosage of SOX3 is critical for normal pituitary development. In-frame duplication or deletion of SOX3 results in the expansion or deletion of the polyalanine tract and has been identified in patients with combined pituitary hormone or isolated growth hormone deficiencies [68-70]. Consistent with our study, in-frame deletion of the polyalanine tract in SOX3 was recently identified in a patient with nIHH [23], suggesting a diverse phenotypic spectrum of polyalanine deletions in SOX3.

In the current study, variants in CHD7 and FGFR1 were found in three ( 3 of 12 variants, $25 \%$ ) and five ( 5 of 12 variants, $41.7 \%$ ) patients, respectively, which were representative of a relatively high proportion of our cohort. Hearing defects represent a significant non-reproductive feature in patients with CHD7 mutations [5]. Midline facial defects, dental agenesis, and skeletal anomalies can indicate mutations in the FGF8/FGFR1 pathway [2]. Bimanual synkinesia and renal agenesis are important clinical clues in ANOS1 mutations [2]. However, in the present study's cohort, these nonreproductive features including hearing defects and syndactyly were noted in only three patients. Of these patients, two had pathogenic CHD7 mutations (Subjects 1 and 3) and one had a novel
FGFR1 variant (Subject 10). The majority of the remaining patients shared a similar phenotype, making it difficult to prioritize genetic variants for screening. Therefore, the application of NGS-based panel testing is an effective diagnostic tool for detecting causative genes in IGD patients with genetic heterogeneity.

Congenital anosmia is a rare condition that can be categorized into isolated or syndromic [71], and KS is a well-described form of syndromic congenital anosmia. Several genetic defects involved in the development and migration of olfactory and $\mathrm{G}$ RH neurons are overlapped by both congenital anosmia and KS [33, 71]. A previous study performed multi-gene panel sequencing including ANOS1, FGF8, FGFR1, PROK2, and PROKR2 in 25 patients with isolated congenital anosmia [33]. As a result, genetic defects in PROK2 and PROKR2 were identified in four unrelated patients [33]. A recent NGS study has suggested that six syndromic KS genes, including ANOS1, CHD7, FGFR1, PROK2, PROKR2, and SEMA3A, are involved in isolated congenital anosmia [71]. In the current study, a pre-pubertal male (Subject 11) with anosmia, who had a history of micropenis and cryptorchidism, harbored a likely pathogenic variant in FGFR1, necessitating a follow-up assessment for pubertal progression.

This study has several limitations. For instance, molecular testing for family members was not performed to validate inheritance patterns and segregation, as the parents' blood samples were not available. In comparison with a previous targeted gene panel study of nIHH/KS [11], we designed a targeted panel that included all 
known IGD-associated genes in humans to reduce the complexity of potential interpretations [11]. When compared to WES and WGS, targeted NGS reduces incidental findings and provides higher sequencing coverage and depth in the targeted regions.

\section{Conclusions}

We achieved a genetic diagnosis in 10 families (37\%) and detected VUS in two patients (7.4\%). In addition, novel pathogenic or likely pathogenic variants were identified in eight probands in ANOS1, CHD7, FGFR1, TACR3, and SOX3. This approach enables rapid, costeffective, and comprehensive genetic screening in patients with IGD.

\section{Funding}

This study was supported by a grant (2017-481) from Asan Medical Center Children's Hospital, Seoul, Korea.

\section{Conflict of Interest}

The authors declare that they have no conflict of interest.

\section{References}

[1] Stamou MI, Cox KH, Crowley WF Jr. Discovering genes essential to the hypothalamic regulation of human reproduction using a human disease model: Adjusting to life in the "-Omics" era. Endocr Rev 2016; 2016: 4-22

[2] Boehm U, Bouloux PM, Dattani MT et al. Expert consensus document: European consensus statement on congenital hypogonadotropic hypogonadism-pathogenesis, diagnosis and treatment. Nat Rev Endocrinol 2015; 11: 547-564

[3] Sykiotis GP, Plummer L, Hughes VA et al. Oligogenic basis of isolated gonadotropin-releasing hormone deficiency. Proc Natl Acad Sci USA 2010; 107: 15140-15144

[4] Pitteloud N, Quinton R, Pearce S et al. Digenic mutations account for variable phenotypes in idiopathic hypogonadotropic hypogonadism. J Clin Invest 2007; 117: 457-463

[5] Costa-Barbosa FA, Balasubramanian R, Keefe KW et al. Prioritizing genetic testing in patients with Kallmann syndrome using clinical phenotypes. J Clin Endocrinol Metab 2013; 98: E943-E953

[6] Au MG, Crowley WF Jr, Buck CL. Genetic counseling for isolated GnRH deficiency. Mol Cell Endocrinol 2011; 346: 102-109

[7] Pedersen-White JR, Chorich LP, Bick DP et al. The prevalence of intragenic deletions in patients with idiopathic hypogonadotropic hypogonadism and Kallmann syndrome. Mol Hum Reprod 2008; 14: $367-370$

[8] Buonocore F, Achermann JC. Human sex development: targeted technologies to improve diagnosis. Genome Biol 2016; 17: 257

[9] Turan I, Hutchins BI, Hacihamdioglu B et al. CCDC141 Mutations in idiopathic hypogonadotropic hypogonadism. J Clin Endocrinol Metab 2017; 102: 1816-1825

[10] Kotan LD, Hutchins BI, Ozkan Y et al. Mutations in FEZF1 cause kallmann syndrome. Am J Hum Genet 2014; 95: 326-331

[11] Quaynor SD, Bosley ME, Duckworth CG et al. Targeted next generation sequencing approach identifies eighteen new candidate genes in normosmic hypogonadotropic hypogonadism and kallmann syndrome. Mol Cell Endocrinol 2016; 437: 86-96
[12] Fraietta R, Zylberstejn DS, Esteves SC. Hypogonadotropic hypogonadism revisited. Clinics 2013; 68: 81-88

[13] Marshall WA, Tanner JM. Variations in the pattern of pubertal changes in boys. Arch Dis Child 1970; 45: 13-23 doi:10.1136/adc.45.239.13

[14] Doty RL, Marcus A, William Lee W. Development of the 12-item cross-Cultural smell identification test (CC-SIT). Laryngoscope 1996; 106: 353-356

[15] Layman LC, Lee EJ, Peak DB et al. Delayed puberty and hypogonadism caused by mutations in the follicle-stimulating hormone beta-subunit gene. N Engl J Med 1997; 337: 607-611

[16] Achermann JC, Weiss J, Lee EJ et al. Inherited disorders of the gonadotropin hormones. Mol Cell Endocrinol 2001; 179: 89-96

[17] Lofrano-Porto A, Barra GB, Giacomini LA et al. Luteinizing hormone beta mutation and hypogonadism in men and women. $\mathrm{N}$ Engl J Med 2007; 357: 897-904

[18] Achermann JC, Jameson JL. Advances in the molecular genetics of hypogonadotropic hypogonadism. J Pediatr Endocrinol Metab 2001; 14: 3-15

[19] Yanase T, Takayanagi R, Oba K et al. New mutations of DAX-1 genes in two Japanese patients with X-linked congenital adrenal hypoplasia and hypogonadotropic hypogonadism. J Clin Endocrinol Metab 1996; 81: 530-535

[20] Martin MG, Lindberg I, Solorzano-Vargas RS et al. Congenital proprotein convertase $1 / 3$ deficiency causes malabsorptive diarrhea and other endocrinopathies in a pediatric cohort. Gastroenterology 2013; 145: 138-148

[21] Reynaud R, Barlier A, Vallette-Kasic S et al. An uncommon phenotype with familial central hypogonadism caused by a novel PROP1 gene mutant truncated in the transactivation domain. J Clin Endocrinol Metab 2005; 90: 4880-4887

[22] Kelberman D, Rizzoti K, Avilion A et al. Mutations within Sox2/SOX2 are associated with abnormalities in the hypothalamo-pituitarygonadal axis in mice and humans. J Clin Invest 2006; 116: 2442-2455 58

[23] Izumi Y, Suzuki E, Kanzaki S et al. Genome-wide copy number analysis and systematic mutation screening in 58 patients with hypogonadotropic hypogonadism. Fertil Steril 2014; 102: 1130-1136 e1133

[24] Salian-Mehta S, Xu M, Knox AJ et al. Functional consequences of AXL sequence variants in hypogonadotropic hypogonadism. J Clin Endocrinol Metab 2014; 99: 1452-1460

[25] Kim HG, Kurth I, Lan F et al. Mutations in CHD7, encoding a chromatin-remodeling protein, cause idiopathic hypogonadotropic hypogonadism and Kallmann syndrome. Am J Hum Genet 2008; 83: 511-519

[26] Miraoui H, Dwyer AA, Sykiotis GP et al. Mutations in FGF17, IL17RD, DUSP6, SPRY4, and FLRT3 are identified in individuals with congenital hypogonadotropic hypogonadism. Am J Hum Genet 2013; 92: 725-743

[27] Tornberg J, Sykiotis GP, Keefe K et al. Heparan sulfate 6-O-sulfotransferase 1 , a gene involved in extracellular sugar modifications, is mutated in patients with idiopathic hypogonadotrophic hypogonadism. Proc Natl Acad Sci U S A 2011; 108: 11524-11529

[28] Quaynor SD, Ko EK, Chorich LP et al. NELF knockout is associated with impaired pubertal development and subfertility. Mol Cell Endocrinol 2015; 407: 26-36

[29] Cariboni A, Davidson K, Rakic S et al. Defective gonadotropin-releasing hormone neuron migration in mice lacking SEMA3A signalling through NRP1 and NRP2: Implications for the aetiology of hypogonadotropic hypogonadism. Hum Mol Genet 2011; 20: 336-344

[30] Kotan LD, Cooper C, Darcan S et al. Idiopathic hypogonadotropic hypogonadism caused by inactivating mutations in SRA1. J Clin Res Pediatr Endocrinol 2016; 8: 125-134 
[31] Chew S, Balasubramanian R, Chan WM et al. A novel syndrome caused by the E410K amino acid substitution in the neuronal beta-tubulin isotype 3. Brain 2013; 136: 522-535

[32] Kim HG, Ahn JW, Kurth I et al. WDR11, a WD protein that interacts with transcription factor EMX1, is mutated in idiopathic hypogonadotropic hypogonadism and Kallmann syndrome. Am J Hum Genet 2010; 87: 465-479

[33] Moya-Plana A, Villanueva C, Laccourreye O et al. PROKR2 and PROK2 mutations cause isolated congenital anosmia without gonadotropic deficiency. Eur J Endocrinol 2013; 168: 31-37

[34] Messina A, Ferraris N, Wray S et al. Dysregulation of Semaphorin7A/ beta1-integrin signaling leads to defective $\mathrm{GnRH}-1$ cell migration, abnormal gonadal development and altered fertility. Hum Mol Genet 2011; 20: 4759-4774

[35] Falardeau J, Chung WC, Beenken A et al. Decreased FGF8 signaling causes deficiency of gonadotropin-releasing hormone in humans and mice. J Clin Invest 2008; 118: 2822-2831

[36] Villanueva C, de Roux N. FGFR1 mutations in Kallmann syndrome. Front Horm Res 2010; 39: 51-61

[37] Bouligand J, Ghervan C, Trabado S et al. Genetics defects in GNRH1: A paradigm of hypothalamic congenital gonadotropin deficiency. Brain Res 2010; 1364: 3-9

[38] Silveira LF, Stewart PM, Thomas M et al. Novel homozygous splice acceptor site GnRH receptor (GnRHR) mutation: Human GnRHR “knockout”. J Clin Endocrinol Metab 2002; 87: 2973-2977

[39] Dedes I. Kisspeptins and the control of gonadotrophin secretion. Syst Biol Reprod Med 2012; 58: 121-128

[40] Aminzadeh M, Kim HG, Layman LC et al. Rarer syndromes characterized by hypogonadotropic hypogonadism. Front Horm Res 2010; 39: 154-167

[41] Beneduzzi D, lyer AK, Trarbach EB et al. Mutational analysis of the necdin gene in patients with congenital isolated hypogonadotropic hypogonadism. Eur J Endocrinol 2011; 165: 145-150

[42] Young J, Bouligand J, Francou B et al. TAC3 and TACR3 defects cause hypothalamic congenital hypogonadotropic hypogonadism in humans. J Clin Endocrinol Metab 2010; 95: 2287-2295

[43] Margolin DH, Kousi M, Chan YM et al. Ataxia, dementia, and hypogonadotropism caused by disordered ubiquitination. $N$ Engl J Med 2013; 368: 1992-2003

[44] Tarnutzer AA, Gerth-Kahlert C, Timmann D et al. Boucher-Neuhauser syndrome: Cerebellar degeneration, chorioretinal dystrophy and hypogonadotropic hypogonadism: Two novel cases and a review of 40 cases from the literature. J Neurol 2015; 262: 194-202

[45] Wolf NI, Vanderver A, van Spaendonk RM et al. Clinical spectrum of $4 \mathrm{H}$ leukodystrophy caused by POLR3A and POLR3B mutations. Neurology 2014; 83: 1898-1905

[46] Handley MT, Aligianis IA. RAB3GAP1, RAB3GAP2 and RAB18: Disease genes in Micro and Martsolf syndromes. Biochem Soc Trans 2012; 40: 1394-1397

[47] Ganos C, Hersheson J, Adams M et al. The $4 \mathrm{H}$ syndrome due to RNF216 mutation. Parkinsonism Relat Disord 2015; 21: 1122-1123

[48] Shi CH, Schisler JC, Rubel CE et al. Ataxia and hypogonadism caused by the loss of ubiquitin ligase activity of the $U$ box protein CHIP. Hum Mol Genet 2014; 23: 1013-1024

[49] Khan SA, Muhammad N, Khan MA et al. Genetics of human bardetbiedl syndrome, an updates. Clin Genet 2016; 90: 3-15

[50] Alsters SI, Goldstone AP, Buxton JL et al. Truncating Homozygous Mutation of Carboxypeptidase E (CPE) in a Morbidly Obese Female with Type 2 Diabetes Mellitus, Intellectual Disability and Hypogonadotrophic Hypogonadism. PLoS One 2015; 10: e0131417
[51] Alazami AM, Al-Saif A, Al-Semari A et al. Mutations in C2orf37, encoding a nucleolar protein, cause hypogonadism, alopecia, diabetes mellitus, mental retardation, and extrapyramidal syndrome. Am J Hum Genet 2008; 83: 684-691

[52] Tata B, Huijbregts L, Jacquier S et al. Haploinsufficiency of Dmxl2, encoding a synaptic protein, causes infertility associated with a loss of GnRH neurons in mouse. PLoS Biol 2014; 12: e1001952

[53] Cukier P, Wright $\mathrm{H}$, Rulfs T et al. Molecular and gene network analysis of thyroid transcription factor 1 (TTF1) and enhanced at puberty (EAP1) genes in patients with GnRH-dependent pubertal disorders. Horm Res Paediatr 2013; 80: 257-266

[54] Harakalova M, van den Boogaard M], Sinke R et al. X-exome sequencing identifies a HDAC8 variant in a large pedigree with X-linked intellectual disability, truncal obesity, gynaecomastia, hypogonadism and unusual face. J Med Genet 2012; 49: 539-543

[55] Francucci CM, Gatti C, Camilletti A et al. Hypogonadism and reduced bone mineral density in heterozygous H63D mutation in the HFE gene: An unusual presentation of hereditary hemochromatosis. J Androl 2007; 28: 21-26

[56] Spiegel R, Shalev SA, Adawi A et al. ANE syndrome caused by mutated RBM28 gene: A novel etiology of combined pituitary hormone deficiency. Eur J Endocrinol 2010; 162: 1021-1025

[57] Pingault V, Bodereau V, Baral V et al. Loss-of-function mutations in SOX10 cause Kallmann syndrome with deafness. Am J Hum Genet 2013; 92: 707-724

[58] McLaren W, Gil L, Hunt SE et al. The Ensembl Variant Effect Predictor. Genome Biol 2016; 17: 122

[59] Sherry ST, Ward MH, Kholodov M et al. dbSNP: the NCBI database of genetic variation. Nucleic Acids Res 2001; 29: 308-311

[60] Landrum M], Lee JM, Riley GR et al. ClinVar: Public archive of relationships among sequence variation and human phenotype. Nucleic Acids Res 2014; 42: D980-D985

[61] Stenson PD, Mort M, Ball EV et al. The Human Gene Mutation Database: building a comprehensive mutation repository for clinical and molecular genetics, diagnostic testing and personalized genomic medicine. Hum Genet 2014; 133: 1-9

[62] Zook JM, Chapman B, Wang J et al. Integrating human sequence data sets provides a resource of benchmark SNP and indel genotype calls. Nature biotechnology 2014; 32: 246-251

[63] Richards S, Aziz N, Bale S et al. Standards and guidelines for the interpretation of sequence variants: a joint consensus recommendation of the American College of Medical Genetics and Genomics and the Association for Molecular Pathology. Genet Med 2015; 17 : 405-424

[64] Brito VN, Batista MC, Borges MF et al. Diagnostic value of fluorometric assays in the evaluation of precocious puberty. J Clin Endocrinol Metab 1999; 84: 3539-3544

[65] Bilan F, Legendre M, Charraud V et al. Complete screening of 50 patients with CHARGE syndrome for anomalies in the CHD7 gene using a denaturing high-performance liquid chromatography-based protocol: New guidelines and a proposal for routine diagnosis. J Mol Diagn 2012; 14: 46-55

[66] Cole LW, Sidis Y, Zhang C et al. Mutations in prokineticin 2 and prokineticin receptor 2 genes in human gonadotrophin-releasing hormone deficiency: Molecular genetics and clinical spectrum. J Clin Endocrinol Metab 2008; 93: 3551-3559

[67] Collignon J, Sockanathan S, Hacker A et al. A comparison of the properties of Sox-3 with Sry and two related genes, Sox-1 and Sox-2. Development 1996; 122: 509-520 
[68] Laumonnier F, Ronce N, Hamel BC et al. Transcription factor SOX3 is involved in X-linked mental retardation with growth hormone deficiency. Am J Hum Genet 2002; 71: 1450-1455

[69] Stagi S, Lapi E, Pantaleo M et al. A SOX3 (Xq26. 3-27.3) duplication in a boy with growth hormone deficiency, ocular dyspraxia, and intellectual disability: A long-term follow-up and literature review. Hormones (Athens) 2014; 13: 552-560
[70] Woods KS, Cundall M, Turton J et al. Over-and underdosage of SOX3 is associated with infundibular hypoplasia and hypopituitarism. Am J Hum Genet 2005; 76: 833-849

[71] Alkelai A, Olender T, Dode C et al. Next-generation sequencing of patients with congenital anosmia. Eur J Hum Genet 2017; 25: 1377-1387 